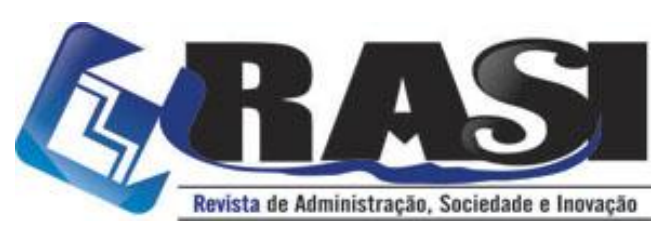

http://www.rasi.uff.br

RASI, Volta Redonda/RJ, v. 5, n. 2, pp. 115-143, mai./ago. 2019

\title{
Interação Universidade-Empresa: características identificadas na literatura e a colaboração regional da Universidade de Twente
}

Eduardo Ferro dos Santos (Universidade de São Paulo) - eduardo.ferro@usp.br

Paul Benneworth (Western Norway University of Applied Sciences \& University of Twente) -

p.benneworth@utwente.nl

\begin{abstract}
RESUMO
É necessário incrementar a inovação através do empreendedorismo acadêmico, fortalecendo a interação entre universidades e empresas, onde a pesquisa sobre modelos de cooperação é necessária. Há muito o que aprender por meio de ações desenvolvidas em outros países, que por meio de modelos emergentes, são uma excelente alternativa para melhorar a qualidade da educação e inovação. Este artigo apresenta duas abordagens metodológicas de pesquisa. Uma primeira, que se refere a uma análise bibliométrica, que identifica lacunas e tendências na relação universidade-empresa. Uma segunda, que por meio de uma pesquisa descritiva, apresenta ações desenvolvidas na Universidade de Twente, na Holanda, demonstrando formas de uma interação emergente de universidade-empresa, que utiliza uma abordagem baseada a inovação aberta, integrando universidade, empresa, sociedade e governo. Com isto, o resultado destas duas abordagens apresenta um modelo emergente que serve de benchmarking de interação, que vai além da transferência usual de conhecimento universitário para a empresa, mas que estabelece formas de cooperação práticas e duradouras.
\end{abstract}

Palavras-Chave: universidade-empresa, empreendedorismo acadêmico, aprendizagem baseada em projetos.

University-Industry Interaction: characteristics identified in the literature and regional collaboration developed by The University of Twente

\section{ABSTRACT}

It is possible to increase innovation by using academic entrepreneurship to strengthen the interaction between universities and companies. There is much to be learned from university-business cooperation actions developed in other countries. Emerging models are an excellent opportunity for improving the quality of education and innovation. This article presents two methodological approaches. The first uses a bibliometric analysis to identify gaps and trends in university-industry relationship. A second descriptive approach presents activities developed at the University of Twente, in the Netherlands, that highlight emerging forms of university-enterprise interaction, using an approach based on open innovation, integrating university, business, society, and government. The result of these two approaches can be used to present an emerging model that serves as an interaction benchmark that goes beyond the usual transfer of university knowledge to companies, but which nevertheless establishes forms of practical and lasting cooperation.

Keywords: university-business interactions, academic entrepreneurship, project-based learning.

\section{Universidade}

R. Desembargador Ellis Hermydio Figueira, 783, Bloco A, sl. 218, Aterrado. 27213-415 - Volta Redonda, RJ - Brasil www.uff.br

Copyright (C) 2019 RASI. Todos os direitos, até mesmo de tradução, são reservados. É permitido citar parte de artigos sem autorização prévia, desde que seja identificada a fonte 


\section{Interação Universidade-Empresa: características identificadas na literatura e a colaboração regional da Universidade de Twente}

\section{Introdução}

As empresas reconhecem cada vez mais que para inovar com sucesso eles não podem confiar exclusivamente em seu setor de pesquisa e desenvolvimento (P\&D). É necessário trabalhar com parceiros externos, que permitem o acesso a diferentes áreas de conhecimento e contribuem para a melhoria dos negócios aos quais a empresa está inserida (Chesbrough, 2003). As universidades estão entre os parceiros externos que mais oferecem estrutura de inovação, uma vez que permitem o acesso a uma enorme variedade global de talentos e habilidades (Markus Perkmann \& Salter, 2012). As ações de Interação Universidade-Empresa (IUE) promovem a competitividade econômica e inovadora das regiões em que se inserem (D'Este \& Patel, 2007).

Nos últimos anos, as IUE apresentaram um enorme interesse como fonte de produção de conhecimento e de novos avanços tecnológicos. Esse interesse é cada vez mais evidente em atividades colaborativas para obter informações de ponta sobre processos de P\&D (Perkmann \& Salter, 2012) e se transforma uma ferramenta para enfrentar os desafios econômicos e sociais (Lehmann \& Menter, 2016; Van Oort \& Frenken, 2010). Empresas no Reino Unido, por exemplo, gastam vinte vezes mais na colaboração com universidades do que no investimento de tecnologias (Chesbrough, 2003).

O Science to Business Marketing Research Centre (S2BMRC, 2018) realizou um estudo sobre a IUE para o Diretório Geral de Educação e Cultura da Comissão Europeia (European Comission, 2018), durante os anos de 2010 e 2011. De acordo com o relatório, os resultados comuns atribuídos a uma bem sucedida IUE incluem: a melhoria da educação; as perspectivas futuras de trabalho dos estudantes; a pesquisa realizada no âmbito da universidade; a transferência de conhecimentos e pesquisa para a comunidade (Davey, Baken, Galan-Muros, \& Meerman, 2011). Este relatório definiu oito maneiras diferentes com as quais as IES e as empresas cooperam:

1. Colaboração em P\&D;

2. Mobilidade dos acadêmicos;

3. Mobilidade dos estudantes;

4. Comercialização dos resultados de P\&D;

5. Desenvolvimento curricular e sua implementação;

6. Aprendizagem ao longo da vida;

7. Empreendedorismo;

8. Governança.

Um resultado fundamental do estudo afirma que a IUE "é um jogo de pessoas". Além disso, "para ambos, acadêmicos e instituições de ensino superior, a existência de confiança mútua, compromisso mútuo e objetivos compartilhados são considerados como indutores essenciais para a boa interação universidade empresa" (Davey et al., 2011: 11). Os ganhos são a ambas as partes, seja no processo de inovação e tecnologia de empresas, como ganhos no processo de ensino e aprendizagem pelas universidades. 
Esta relação entre universidades e empresas tem vindo a ser amplamente discutida, pela diversidade de iniciativas e atividades que podem ser preconizadas em parceria (Thune, 2011). Geralmente, a transferência de tecnologia é o elo comum entre universidades e empresas (Chesbrough, 2003), levando-as assim a estabelecer estratégias centradas na cooperação num sentido, integrando pesquisa e desenvolvimento. Contudo, estas parcerias cingem-se aos contextos específicos em que os participantes se inserem e às ações que se desenvolvem, não ficando clara a forma duradoura de estabelecer relações de cooperação entre universidades e empresas (Person \& Rosenbaum, 2006). Estas relações são identificadas na literatura como complexas mas altamente necessárias para o desenvolvimento das sociedades (D'Este \& Patel, 2007; Etzkowitz, Webster \& Healey, 1998; Thune, 2009). Cada qual assume a sua especificidade que, integradas, podem conduzir à inovação tecnológica, portanto, baseada numa interação com ganhos para os dois lados.

As universidades estão direcionadas para responder a estímulos originados no âmbito puramente científico e tecnológico e, nesse sentido, são atores chaves do processo de inovação e de difusão de tecnologia no âmbito da interação entre agentes distintos (Cohen, Nelson \& Walsh, 2002), pois elas são fontes gerais de conhecimentos necessários para as atividades de pesquisa básica, bem como são fontes de conhecimento especializado relacionado à tecnologia aplicadas nas empresas, além de serem responsáveis pela formação de profissionais altamente qualificados com competência para solucionar problemas relativos ao processo de inovação tecnológica das empresas.

Embora haja estas vantagens, universidades e empresas tem tido dificuldades em manter interações de longo prazo em projetos que envolvem equipes de estudantes atuando na resolução de problemas reais, a fim de que, os alunos possam vivenciar a prática profissional. Um estudo apresentou os trinta melhores estudos de caso das boas práticas para uma boa IUE na Europa (Davey et al., 2011), mas de todo o conjunto de estudos de caso, apenas um está relacionado com desenvolvimento curricular e sua implementação, e está baseado no desenvolvimento de ideias de negócios dos estudantes apoiados por mecanismos de financiamento e de difícil manutenção.

Isso confirma que há uma falta de estudos e desenvolvimentos relacionados com as interações bidirecionais sustentáveis entre universidades e indústrias centrados nos alunos e em modelos de aprendizagem. O relatório final deste estudo, sobre a IUE revelou que, apesar de atividades operacionais serem percebidas como as mais desenvolvidas partes de uma IUE, elas estão apenas moderadamente desenvolvidas, e há a necessidade de desenvolver ferramentas e metodologias em torno de parcerias de longo prazo. Além disso, desenvolver atividades que facilitem a interação de estudantes com negócios é considerada a atividade com o maior impacto numa IUE (Davey et al., 2011).

As universidades estão preparando profissionais para essas indústrias e as indústrias podem se beneficiar desta interação, explorando a oportunidade de melhorar e inovar os seus produtos ou processos. Sendo assim, a fim de criar interações sustentáveis, é necessário estudar os diferentes modelos de projetos, definir indicadores chave de desempenho e avaliar estes modelos.

Sendo assim, a importância da pesquisa neste assunto pode ser medida pelo número de publicações acadêmicas que abordam estas interações, em busca de oportunidades de trabalhos futuros sugeridos nas mesmas. Este é um dos objetivos deste trabalho, onde para abordar os 
recentes desafios desta área e as oportunidades de pesquisa, realizou-se neste trabalho uma análise bibliométrica quantitativa de artigos revisados por pares em IUE. Assim, pode-se compreender além da evolução do tema, as oportunidades e desafios, sendo estes cruciais para ambas as partes (D’Este, Guy, \& Iammarino, 2013). Em uma segunda abordagem, que se relaciona a um segundo objetivo deste trabalho, um estudo descritivo e exploratório (Gil, 2002; Santos, 2008a, 2008b) foi realizado na Universidade de Twente, Holanda, onde são apresentada ações de IUE. O resultado destas duas abordagens apresenta um modelo emergente que serve de benchmarking de interação, que vai além da transferência usual de conhecimento universitário para a empresa, mas que estabelece formas de cooperação práticas e duradouras baseada em um conceito de Quadruple Helix (Afonso, Monteiro \& Thompson, 2012; Parveen, Senin \& Umar, 2015).

\section{Modelos de IUE}

Na literatura, encontram-se diversos modelos, sendo os principais o Estadista, a Triple Helix, o Laissez-Faire, o de Inovação Aberta e os Modos Emergentes, baseados em modelos de ensino e redes de cooperação.

O primeiro modelo, denominado "Estadista", surgiu na década de 1960, na América Latina (Sábato \& Botana, 1968), que já salientavam o papel da interação entre indústria e as universidades por meio do governo, sendo este o principal elemento na criação de ações para a intermediação, sendo a responsabilidade quase que exclusiva por esta parte. A Figura 1 demostra esta relação por meio de uma pirâmide de relacionamento.

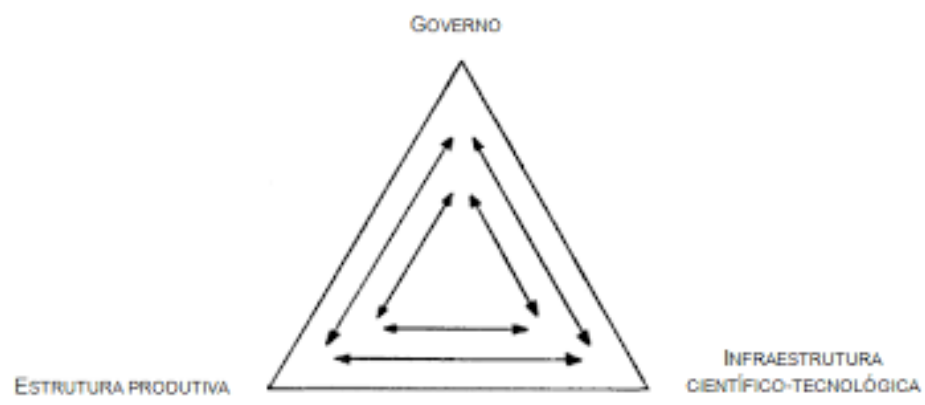

Figura 1 - Modelo Estadista (Sábato \& Botana, 1968)

Esse modelo foi muito utilizado de forma implícita em diversos países, como os EUA nas duas guerras mundiais, e no Brasil entre os anos de 1970 e 1980 por meio de financiamentos em larga escala realizados pelo governo brasileiro (Etzkowitz, 2013).

Um segundo modelo é denominado de modelo "Laissez-Faire", sendo que para este tanto o governo, quanto as universidades e empresas atuam de maneira separada. Neste modelo, o papel da universidade é o de promover a pesquisa, gerando publicações científicas e o desenvolvimento de recursos humanos para as empresas, cabendo a empresas operacionalizar de maneira isolada seu processo de desenvolvimento tecnológico por meio dos seus departamentos de P\&D (Etzkowitz, 2013). A Figura 2 apresenta esta relação mútua na pirâmide. 


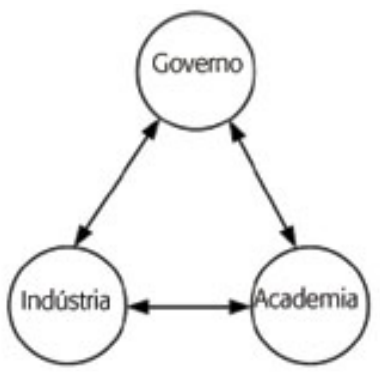

Figura 2 - Laissez-Faire (Etzkowitz, 2013)

O modelo da "Triple Helix" ou a teoria do campo da hélice tríplice foi desenvolvido por Etzkowitz e Leydesdorff (Etzkowitz \& Leydesdorff, 1997) e tem evidenciado uma abordagem de entendimento acerca das relações para a geração de inovação, já que as universidades podem contribuir além do seu papel de pesquisa básica, passando a interagir com as empresas por meio do processo de transferência tecnológica e de conhecimento. A universidade torna-se um dos propulsores de desenvolvimento regional e econômico (College \& Road, 2004; Etzkowitz, 2013; Etzkowitz \& Leydesdorff, 1997; Ranga \& Etzkowitz, 2013). A Figura 3 mostra as relações deste modelo.

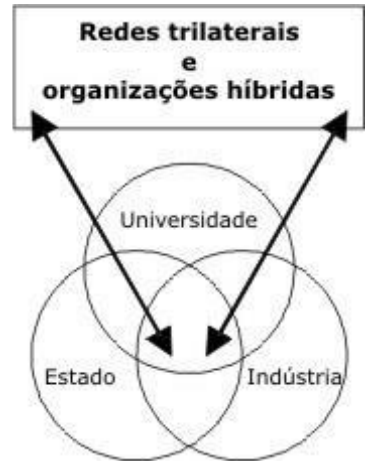

Figura 3 - Triple Helix (Etzkowitz \& Ranga, 2010)

Dada a dinâmica das mudanças ocorridas no contexto das relações globais para a geração de inovações tecnológicas, novos modelos emergem. Estes vêm sendo discutidos dentro das pesquisas sobre IUE como forma de ampliar e diversificar a compreensão dos fenômenos estudados. Entre elas destacam-se o modelo "Inovação Aberta" (IA) (Chesbrough, 2003) ou sistemas nacionais de inovação" (Freeman, 1988; Motohashi, 2005). O conceito de inovação aberta propõe uma mudança no modo tradicional das empresas inovarem, trata-se de uma quebra de paradigma no processo inovativo. O conceito de IA altera o fluxo do relacionamento entre as empresas, as instituições de pesquisa e o mercado no processo de inovação, tornandose colaborativo (Chesbrough, 2003). Busca-se absorver o conhecimento e experiência, rompendo as fronteiras de aprendizagem com os outros participantes deste processo (Silva, Bagno, \& Salerno, 2013). O fluxo do modelo é entendido na Figura 4, que mostra como é realizado a pesquisa e o desenvolvimento e como a colaboração pode ocorrer neste sentido.

Isto propicia o relacionamento em conjunto entre dois ou mais integrantes no processo de inovação. Essa relação pode ocorrer entre os seguintes atores: fornecedores, consumidores, competidores, intermediários ou Instituições de Ciência e Tecnologia (Chesbrough \& Schwartz, 2007). 
O modelo IA é o modelo mais emergente, pois por meio de metodologias ativas de ensino e aprendizagem, pode-se estimular as ideias que levam aos novos projetos, estimulando a criação de novos segmentos, tais como startups (Calcagnini, Favaretto, Giombini, Perugini \& Rombaldoni, 2016; Tötterman \& Sten, 2005), spin-offs (Clarysse, Wright \& Van de Velde, 2011), incubadoras (Fallis, 2013), dentre outros, além de dar apoio a sociedade na resolução de problemas também emergentes.

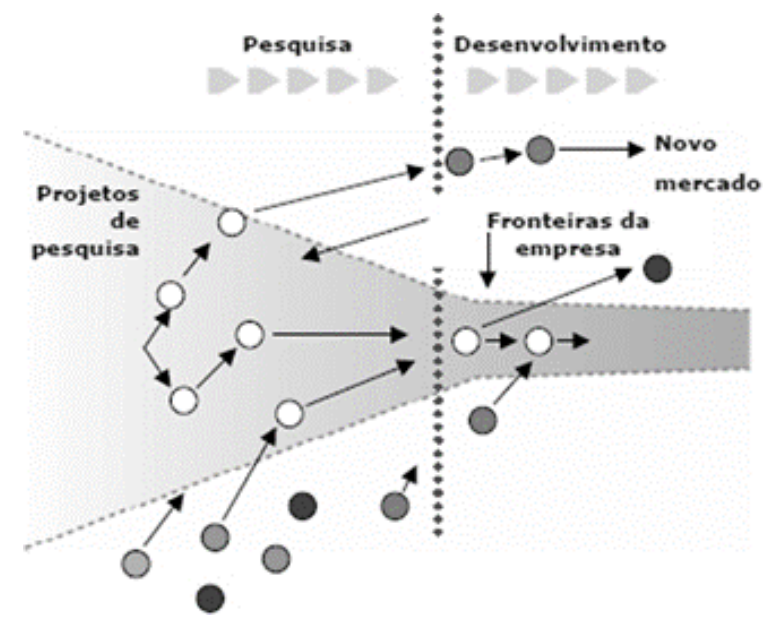

Figura 4 - Inovação Aberta (H. W. Chesbrough, 2003)

Com base no modelo de IA, fala-se então de modelos que desenvolvem habilidades e competências baseadas em resultados e no mercado, incluindo as metodologias de ensino e aprendizagem com foco no aluno, por meio do desenvolvimento de competências. Estas são as principais abordagens de um projeto que, para desenvolver tais abordagens, devem possuir uma rede estabelecida de comunidades interconectadas de praticantes e aprendizes de universidades e empresas, sendo uma rede de cooperação universidade, empresa e sociedade. Sendo assim, surgem as redes, tais como a EMCOSU - Emerging Modes of Cooperation between Private Sector Organisations and Universities (Melink, Pušnik \& Pavlin, 2014) como um projeto bem sucedido de IUE, além da UIIN (UIIN, 2018), que integram linhas de pesquisa adotadas por projetos de todo o mundo, validando a relevância da colaboração entre empresas e universidades, se interessando na formulação de políticas de ensino superior.

Uma das principais atuações do EMCOSU é destacar a todas as partes a importância das habilidades e competências que os graduados devem adquirir (Deželan, Laker, \& Pavlin, 2016), já que elas ajudam a melhorar as capacidades inovadoras das empresas. Essas percepções encorajam melhorias nas políticas no campo do ensino de metodologias de aprendizagem para que novos perfis e modelos sejam criados.

Estas práticas reforçam a ligação entre as atividades de educação e as necessidades de empregabilidade dos graduados do ensino superior e promove a cooperação com os instrumentos de ensino superior em particular (Melink et al., 2014) Os principais mecanismos nacionais e internacionais que fornecem indicações para contribuir com esse objetivo estão intimamente relacionados à cooperação entre instituições de ensino superior e empresas, o que representa o foco principal do projeto.

Considerando então modelos baseados em redes de cooperação, emergem ainda modelos de redes globais que agregam objetivos em comum. Um exemplo, são as iniciativas de projetos 
por um mundo melhor, como o da Agenda 2030 (United Nations, 2015). Esta Agenda, desenvolvida pela Organização das Nações Unidas (ONU), sugere que os países membros formalmente adotem os dezessete Objetivos de Desenvolvimento Sustentável (ODS) como elementos-chave, com 169 metas estratégicas, que são integradas e equilibram as três dimensões do desenvolvimento sustentável: econômica, social e ambiental (COLGLAZIER, 2015). Para atingir estes resultados, redes de cooperação que integram universidade, empresas, governos e sociedade surgem, como a rede "Sustainable Development Solutions Network (SDSN)", organizada pelo International Institute for Applied Systems Analysis (IIASA) e Stockholm Resilience Center (SRC) (SDSN, 2018). A rede também denominada TWI2050 The Word in 2050 (IIASA, 2018) é uma iniciativa de pesquisa global em apoio à implementação bem sucedida da Agenda 2030 da ONU. O objetivo é fornecer o conhecimento para apoiar o processo de políticas e a implementação dos ODS. As parcerias do IIASA existem em todos os níveis: as organizações nacionais membros do instituto, agencias e empresas financiadores de pesquisa, agências e programas da ONU e outras organizações internacionais, universidades e outras instituições de ensino, organizações como ONGs, e o setor público e privado.

Há outras maneiras pelas quais as atividades de IUE ocorrem, desde a cooperação na elaboração e entrega de cursos, passando pela mobilidade de funcionários e estudantes (por períodos variáveis), até o fornecimento de recursos e instalações. Na prática, a maioria das atividades envolve mais de uma forma de cooperação. O nível de cooperação também pode mudar com o tempo, à medida que as atividades amadurecem, evoluem, ou atingem o final de sua vida útil.

\section{A análise bibliométrica}

Para apontar a evolução do assunto, se faz necessária uma pesquisa bibliográfica como fundamento para a criação de novos conhecimentos. Dentre os possíveis objetivos das pesquisas bibliográficas, temos: o levantamento dos pareceres de outros pesquisadores sobre o estudo a ser pesquisado, a identificação de lacunas investigativas, a utilização, como material de estudo, dos trabalhos desenvolvidos por outros pesquisadores, dentre outros (Medeiros, Vieira, Braviano \& Gonçalves, 2015).

A importância da pesquisa é medida pelo número de publicações acadêmicas que aborda o assunto e pelas oportunidades de trabalhos futuros sugeridos nas publicações. Para abordar estes desafios desta área e as oportunidades de pesquisa, realizou-se neste trabalho uma análise bibliométrica quantitativa de artigos revisados por pares. Assim, pode-se também compreender os desafios e oportunidades das IUE, pois estes desafios também se tornaram um cruciais para ambas as partes (D'Este et al., 2013).

Pesquisa acadêmicas podem nortear as empresas e universidades e contribuir de forma significativa com a proposição de ferramentas de gestão para a utilização dos princípios da IUE. Afim de identificar em que direção a literatura se desenvolve e de buscar oportunidades de pesquisa em relação a este tema, é realizada uma análise bibliométrica do assunto.

A bibliometria é a prática da ciência que compreende o uso de ferramentas matemáticas e estatísticas com o objetivo de analisar e medir a literatura em um determinado campo de conhecimento (Huang et al., 2016). Compreende à análise quantitativa de dados para investigar quais são suas propriedades e como se comporta a evolução das informações científicas 
(Ferreira, Santos, de Almeida \& Reis, 2014). É uma ferramenta importante para investigar o campo de pesquisa sobre a IUE e para identificar sua origem e evolução.

Pelo exposto, o objetivo deste trabalho é identificar qual é o estado da arte da literatura sobre IUE, quais são as oportunidades e tendências da pesquisa no assunto. Para isto, foram mapeados a produção científica dos artigos, pesquisadores, instituições, periódicos e países mais relevantes, refletindo a evolução da literatura em um determinado período de tempo (GomezJauregui, Gomez-Jauregui, Manchado \& Otero, 2014).

Foi realizada uma análise bibliométrica sobre o tema IUE, buscando a inclusão de autores e publicações relevantes. Para isso, foi selecionada a bases de dados Web of Science (WOS), da Clarivate Analytics por conter publicações científicas de alta qualidade e grande impacto na comunidade científica (Guerrero-Bote \& Moya-Anegón, 2012).

O processo de busca de trabalhos na WOS utilizou as palavras-chaves "University" e "Industry" no título, visando obter resultados de qualquer forma de interação. Inicialmente foram encontradas 2.402 ocorrências. O primeiro filtro utilizado na bibliometria foi a restrição das publicações para artigos (932) e publicações em eventos (919), totalizando então 1793 ocorrências. Este filtro foi adotado para aumentar a precisão dos resultados, entendendo-se que eles permitem uma identificação mais precisa e confiável das lacunas científicas relacionadas ao tema. O último filtro foi a delimitação de trabalhos publicados nos anos de 2007 a 2017 para melhor compreensão do estado da arte da IUE e a identificação de lacunas científicas atuais para promover e orientar novos estudos sobre o tema. Foram encontrados 1003 documentos.

Ao final de todos os critérios estabelecidos e filtros aplicados, foi possível identificar a relevância dos artigos, autores, países, instituições e revistas relacionados ao tema, além da ocorrência das palavras-chave e a evolução das publicações ao longo do tempo. A avaliação da relevância de publicações científicas foi realizada de acordo com o número de citações recebidas (Bornmann, Haunschild \& Marx, 2016). Esta relevância dos autores, artigos, países e instituições foram relacionadas conforme o número de citações, e a relevância dos periódicos, conforme o número médio de citações por documento.

A Figura 5 mostra as publicações por ano, indicando em 1945 (limitações dadas na WOS). Percebe-se que houve um aumento significativo da importância científica da IUE. A primeira publicação é do ano de 1944. O trabalho intitulado "Merits and defects of present practises of cooperation between universities and industry" foi publicado na revista School and Society (Payne, 1921).

A evolução das publicações é então apresentada em uma série temporal de 1945 a 2017 . Há um crescimento visível nas publicações que se inicia a partir de 1990, mais visível ainda a partir do ano 2000. Percebe-se que no período escolhido para esta pesquisa, de 2007 a 2017, há um crescimento significativo, exponencial, dando a esta área de atuação uma faixa de atenção especial pelos pesquisadores. 


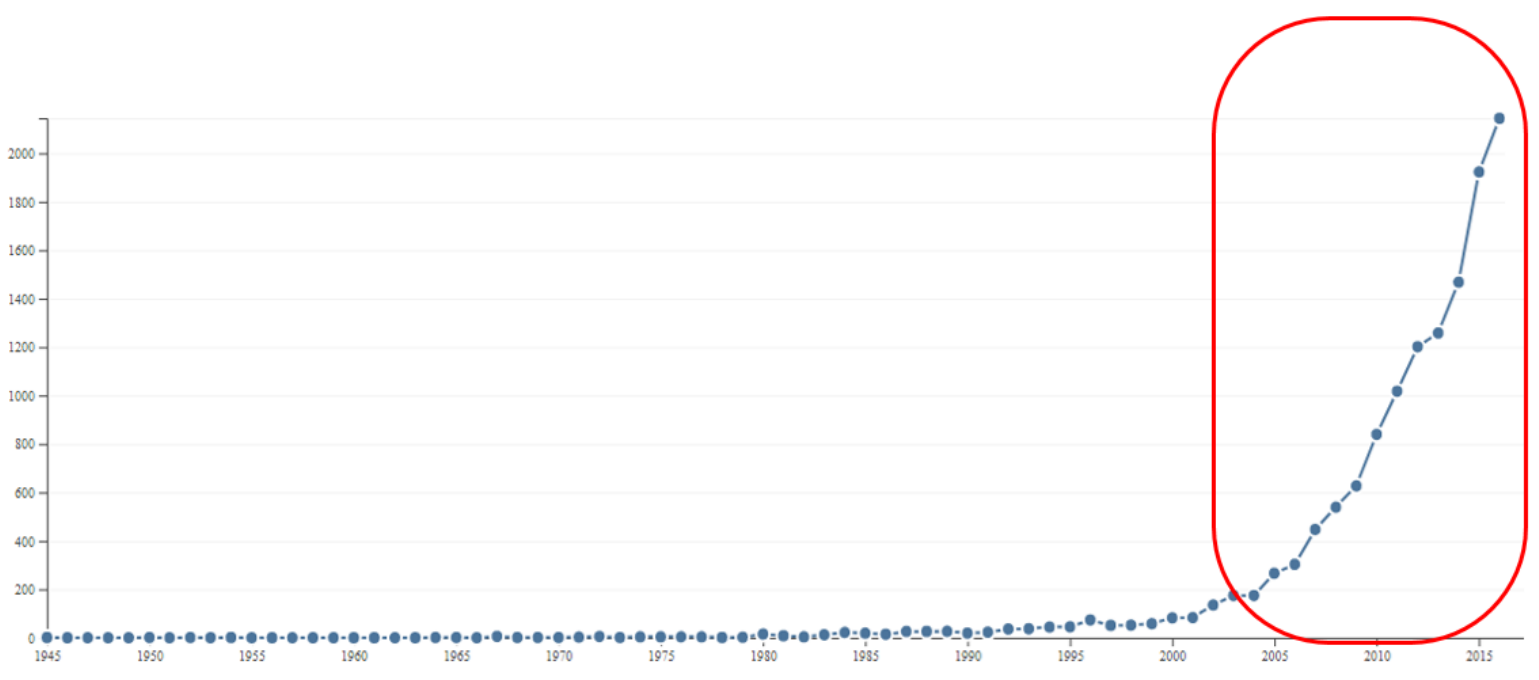

Figura 5 - Evolução desde a primeira publicação

Nas subseções seguintes, as subáreas, os países, os periódicos, as instituições, artigos e autores sobre IUE são analisadas no período de 2007 a 2017.

\subsection{Análise das subáreas}

A Figura 6 apresenta a distribuição dos artigos sobre IUE publicados de acordo com as suas respectivas subáreas de pesquisa.

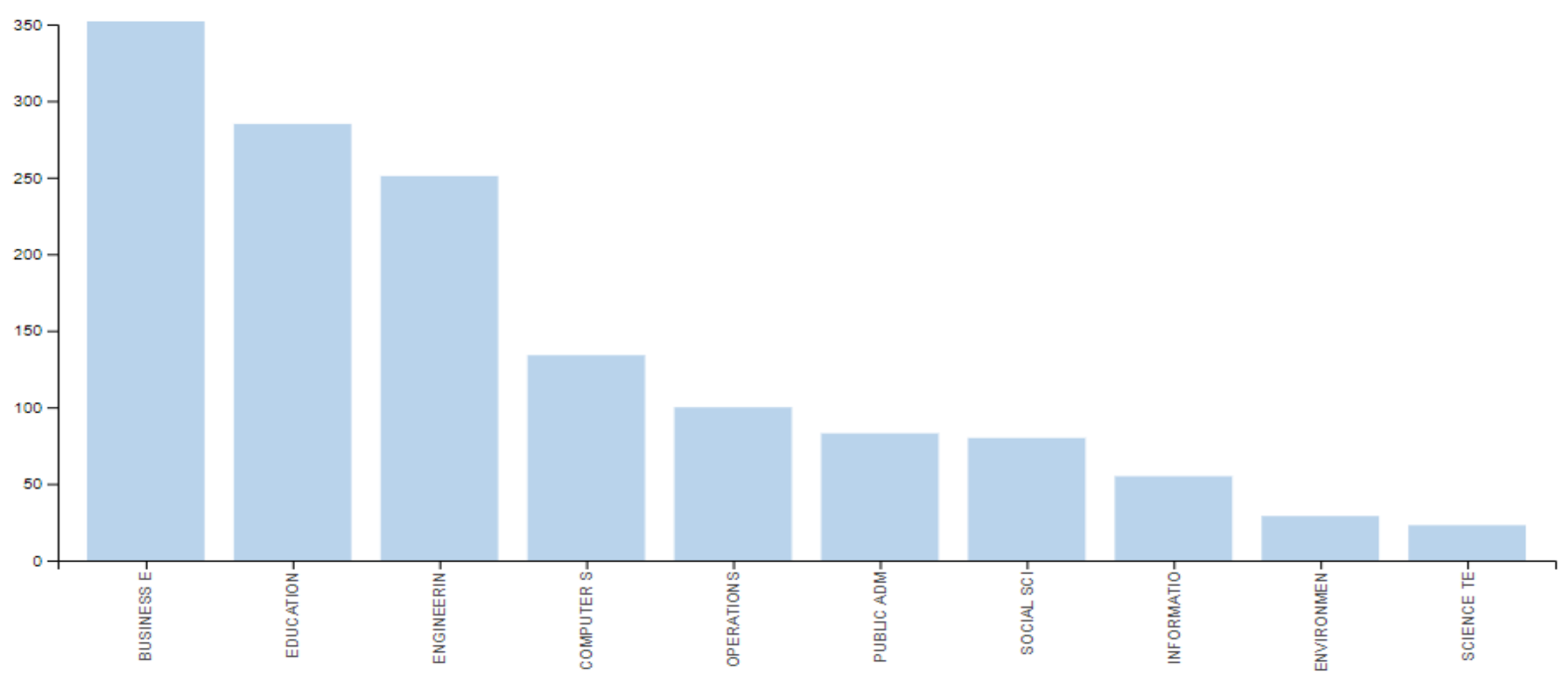

Figura 6 - Principais Subáreas da IUE

Apesar dos termos serem empregados em várias subáreas de pesquisa, a Figura 6 destaca sua concentração nas áreas de gestão (administração e economia), ensino e engenharia. A área de gestão se distancia (350 ocorrências) significativamente das áreas de educação (283 ocorrências) e engenharia (249 ocorrências), que se distanciam significativamente das demais áreas (a partir de 312 ocorrências).

\subsection{Análise dos países}


Serão apresentados na Figura 7, os países mais relevantes conforme o número de publicações em IUE. Dentre eles está a China com 261 ocorrências, mais que o dobro dos Estados Unidos, com 127. O Brasil ocupa a $13^{\circ}$ colocação, com 21 ocorrências. Um importante comentário é dado em relação ao crescimento da China na economia mundial (Ribeiro, 2018), sendo atualmente também o país com mais publicações sobre IUE.

Como exemplo da dominância dos países desenvolvidos nas 10 primeiras colocações, surge para o Brasil em desenvolvimento, a necessidade e oportunidade de pesquisa na área. O Brasil não tem nem $10 \%$ das publicações da China, apesar de estar à frente do Canadá no assunto. Este tema tão abrangente e reconhecido de forma global, precisa ser mais explorado para identificar o que vem sendo feito e quais são as tendências de pesquisas futuras.

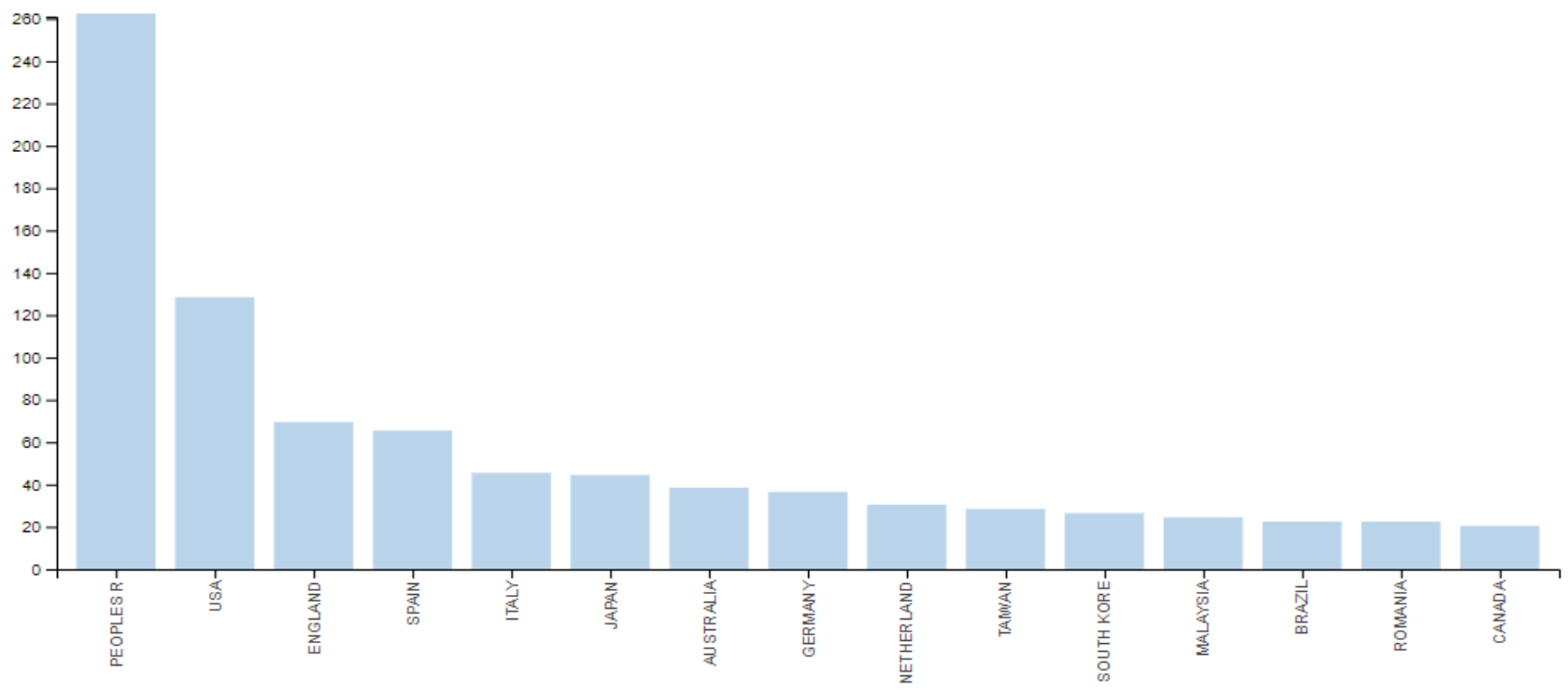

Figura 7 - Países com maior número de documentos e citações

\subsection{Análise dos periódicos}

Os dez periódicos mais citados sobre IUE podem ser vistos na Tabela 1, que apresenta o nome do periódico com a contagem de ocorrências. Os três títulos de fonte que obtiveram maior número médio de citações por documento são representados pelo "ICERI Proceedings", "INTED Proceedings" e o "Advances in Social Science Education and Humanities Research", sendo os dois primeiros relacionados a conferências e este último ( $3^{\circ}$ colocado $)$ ou periódico de maior ocorrência das publicações.

Tabela 1- Periódicos mais citados

\begin{tabular}{|c|c|}
\hline Títulos da Fonte & Contagem do Registro \\
\hline ICERI Proceedings & 34 \\
\hline INTED Proceedings & 34 \\
\hline
\end{tabular}

Fonte: Web of Science

Tabela 1- Periódicos mais citados (continuação)

\begin{tabular}{|c|c|}
\hline Títulos da Fonte & Contagem do Registro \\
\hline
\end{tabular}




\begin{tabular}{|c|c|}
\hline Advances in Social Science Education and Humanities Research & 31 \\
\hline Research Policy & 29 \\
\hline Journal of Technology Transfer & 26 \\
\hline Procedia Social and Behavioral Sciences & 23 \\
\hline Scientometrics & 23 \\
\hline ASEE Annual Conference Exposition & 22 \\
\hline Portland International Conference on Management of Engineering and Technology & 21 \\
\hline Edulearn Proceedings & 18 \\
\hline
\end{tabular}

Fonte: Web of Science

\subsection{Análise das instituições}

É importante para o estado da arte, saber quais as instituições que mais publicam no assunto nos últimos anos. A Tabela 2 apresenta as dez instituições dos primeiros autores mais citados sobre IUE com seus respectivos países, número de documentos e número de citações.

As instituições que mais publicaram nos últimos anos são "Wuhan University of Technology" (China), a "University of London Imperial College" (Inglaterra) e empatados na terceira posição a "Harbin Institute of Technology" (China) e a "Universidad Politecnica de Valencia" (Espanha). Destaca-se que na análise das instituições, a China também tem mais que o dobro de publicações do $2^{\circ}$ colocado, sendo 24 no total. Se ainda somarmos as universidades chinesas, 4 entre as 10, totaliza-se 50 ocorrências, sendo evidentemente o país mais contributivo no assunto.

Tabela 2 - Instituições que mais publicam

\begin{tabular}{|c|c|}
\hline Organizações & Contagem do Registro \\
\hline Universidade de Tecnologia de Wuhan & 34 \\
\hline Universidade de Londres - Colégio Imperial & 34 \\
\hline Instituto de Tecnologia de Harbin & 31 \\
\hline Universidade Politécnica de Valência & 29 \\
\hline Universidade de Amsterdã & 26 \\
\hline Universidade do Minho & 23 \\
\hline Universidade de Zhejiang & 23 \\
\hline Universidade tecnológica de Lublin & 22 \\
\hline Universidade de Sichuan & 21 \\
\hline Universidade de Tóquio & 18 \\
\hline
\end{tabular}

Fonte: Web of Science 


\subsection{Análise dos artigos}

Na Tabela 3 são apresentados os títulos dos artigos mais relevantes sobre o tema, seus autores, periódicos nos quais foram publicados, ano de publicação do artigo, total de citações do artigo até o dia 12 de janeiro de 2018, média de citações por ano e a evolução destas citações no período de 2007 a 2017. Cabe ressaltar, que ao realizar a busca por títulos, quando o mesmo não deixava claro se o artigo se enquadrava no escopo deste estudo, o resumo dos artigos auxiliou nesta classificação.

$\mathrm{O}$ artigo "University-industry linkages in the UK: What are the factors underlying the variety of interactions with industry?" (P. D'Este \& Patel, 2007) é o artigo mais relevante encontrado na literatura sobre IUE com um total de 399 citações até o dia 12 de janeiro de 2018, praticamente o dobro do terceiro colocado. Percebe-se também que o periódico acadêmico "Research Policy" é o mais procurado pelos pesquisadores e IUE.

Embora não seja objetivo observar o autor mais citado, é evidente a presença do autor D'Este (Pablo D'Este) que aparece em três dos dez artigos mais citados, sendo o primeiro autor em duas publicações. Pode-se então assegurar com esta base de dados que D'Este é o autor mais citado no assunto, embora pela análise dos autores não tenha sido o mais produtivo. D'Este é Doutor em Economia, professor da titular da Universidade Politécnica de Valencia na Espanha.

Tabela 3 - Artigos mais citados entre 2007 a 2017

\begin{tabular}{|c|c|c|c|c|c|c|}
\hline $\mathbf{N}$ & Título & Periódico & Ano & Citações & $\begin{array}{c}\text { Média de } \\
\text { citações / ano }\end{array}$ & Evolução no período \\
\hline 1 & $\begin{array}{l}\text { University-industry linkages in } \\
\text { the UK: What are the factors } \\
\text { underlying the variety of } \\
\text { interactions with industry? } \\
\text { (D'Este \& Patel, 2007) }\end{array}$ & $\begin{array}{c}\text { Research } \\
\text { Policy }\end{array}$ & 2007 & 399 & 33,25 & (10) \\
\hline 2 & $\begin{array}{l}\text { Investigating the factors that } \\
\text { diminish the barriers to } \\
\text { university-industry collaboration } \\
\text { (Bruneel, D'Este, \& Salter, } \\
\text { 2010) }\end{array}$ & $\begin{array}{c}\text { Research } \\
\text { Policy }\end{array}$ & 2010 & 246 & 27,33 & (10) \\
\hline 3 & $\begin{array}{l}\text { Analysing knowledge transfer } \\
\text { channels between universities } \\
\text { and industry: To what degree do } \\
\text { sectors also matter? (Bekkers \& } \\
\text { Bodas Freitas, 2008) }\end{array}$ & $\begin{array}{c}\text { Research } \\
\text { Policy }\end{array}$ & 2008 & 200 & 18,18 & (15 \\
\hline 4 & $\begin{array}{l}\text { Beyond industry-university } \\
\text { links: Sourcing knowledge for } \\
\text { innovation from consultants, } \\
\text { private research organisations } \\
\text { and the public science-base } \\
\text { (Tether \& Tajar, 2008) }\end{array}$ & $\begin{array}{c}\text { Research } \\
\text { Policy }\end{array}$ & 2008 & 185 & 16,82 & (15) \\
\hline
\end{tabular}

Fonte: Elaboração própria 
Tabela 3 - Artigos mais citados entre 2007 a 2017 (continuação)

\begin{tabular}{|c|c|c|c|c|c|c|}
\hline $\mathbf{N}$ & Título & Periódico & Ano & Citações & $\begin{array}{c}\text { Média de } \\
\text { citações / ano }\end{array}$ & Evolução no período \\
\hline 5 & $\begin{array}{l}\text { Why do academics engage with } \\
\text { industry? The entrepreneurial } \\
\text { university and individual } \\
\text { motivations (Pablo D'Este \& } \\
\text { Perkmann, 2011) }\end{array}$ & $\begin{array}{l}\text { Journal of } \\
\text { Technolog } \\
\text { y Transfer }\end{array}$ & 2011 & 160 & 20 & (15 \\
\hline 6 & $\begin{array}{l}\text { Mid-range universities' linkages } \\
\text { with industry: Knowledge types } \\
\text { and the role of intermediaries } \\
\text { (Pablo D'Este \& Perkmann, } \\
\text { 2011) }\end{array}$ & $\begin{array}{c}\text { Research } \\
\text { Policy }\end{array}$ & 2008 & 143 & 13 & (20) \\
\hline 7 & $\begin{array}{l}\text { Innovation, spillovers and } \\
\text { university-industry } \\
\text { collaboration: an extended } \\
\text { knowledge production function } \\
\text { approach (Ponds et al., 2010) }\end{array}$ & $\begin{array}{l}\text { Journal of } \\
\text { Economic } \\
\text { Geography }\end{array}$ & 2010 & 132 & 14,67 & 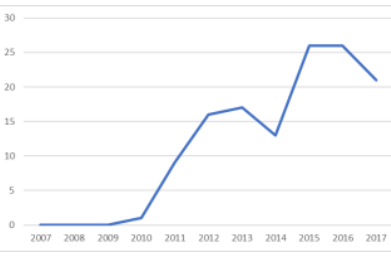 \\
\hline 8 & $\begin{array}{c}\text { Exploring the Effect of } \\
\text { Geographical Proximity and } \\
\text { University Quality on } \\
\text { University-Industry } \\
\text { Collaboration in the United } \\
\text { Kingdom (Laursen, Reichstein, } \\
\text { \& Salter, 2011) }\end{array}$ & $\begin{array}{c}\text { Regional } \\
\text { Studies }\end{array}$ & 2011 & 103 & 12,88 & 0 \\
\hline 9 & $\begin{array}{l}\text { The two faces of collaboration: } \\
\text { impacts of university-industry } \\
\text { relations on public research (M. } \\
\text { Perkmann \& Walsh, 2009) }\end{array}$ & $\begin{array}{l}\text { Industrial } \\
\text { and } \\
\text { Corporate } \\
\text { Change }\end{array}$ & 2009 & 101 & 10,1 & (16) \\
\hline 10 & $\begin{array}{l}\text { Sources of innovation and } \\
\text { industry-university interaction: } \\
\text { Evidence from Spanish firms } \\
\text { (Segarra-Blasco \& Arauzo- } \\
\text { Carod, 2008) }\end{array}$ & $\begin{array}{c}\text { Research } \\
\text { Policy }\end{array}$ & 2008 & 100 & 9,09 & (16) \\
\hline
\end{tabular}

Fonte: Elaboração própria 


\subsection{Análise dos autores}

Embora D'Este tenha os trabalhos mais citados, não aparece entre os dez mais produtivos (e número de publicações). A análise dos autores aponta para "Loet Leydesdorff" como o autor mais produtivo, não muito distanciado de "Juan Igartua", com a diferença de apenas um trabalho no período.

Tabela 4 - Autores mais citados entre 2007 a 2017

\begin{tabular}{|c|c|c|c|c|}
\hline $\mathbf{N}$ & Autor & Instituição & Número de trabalhos & País \\
\hline 1 & Leydesdorff, Loet & University of Amsterdam & 9 & Holanda \\
\hline 2 & Igartua, Juan & Mondragon University & 8 & Espanha \\
\hline 3 & Huang, Mu-Hsuan & National Taiwan University & 6 & China \\
\hline 4 & Muscio, Alessandro & Univ Foggia & 5 & Itália \\
\hline 5 & Azagra-Caro, Joaquin M & Univ Politecn Valencia & 5 & Espanha \\
\hline 6 & Biscotti, Dina & Univ Calif Davis & 5 & China \\
\hline 7 & Chen, Dar-Zen & Natl Taiwan Univ & China \\
\hline 8 & Chen, Jin & Zhejiang Univ & 5 & Romênia \\
\hline 9 & Draghici, Anca & Politehn Univ Timisoara & 5 & Espanha \\
\hline 10 & Errasti, Nekane & Mondragon Univ & & 5 \\
\hline
\end{tabular}

Fonte: Web of Science

Leydesdorff tem nove trabalhos relacionados a IUE no período, com 220 citações no período. Seu último trabalho é intitulado "Decomposing the Triple-Helix synergy into the regional innovation systems of Norway: firm data and patent networks" (Strand, Ivanova \& Leydesdorff, 2017). Seu trabalho mais citado é o "Longitudinal trends in networks of university-industry-government relations in South Korea: The role of programmatic incentives" (Park \& Leydesdorff, 2010), com 83 citações. Loet Leydesdorff é Doutor em Sociologia, professor da University of Amsterdam.

\subsection{Identificação de oportunidades de pesquisa}

A partir da leitura dos artigos dos autores mais citados, é possível identificar oportunidades de pesquisa a serem exploradas. Estes trabalhos são evidenciados no Anexo 1. Para avaliar estas oportunidades de pesquisa, os artigos publicados entre 2007 e 2017 foram analisados com relação aos temas "gaps" que eles tratam.

O processo de identificação de gaps sobre o tema foi conduzido para identificar sugestões dadas pelos autores quanto aos avanços que são necessários em cada um dos dez artigos mais recentes dos autores mais citados. Foram pesquisados os artigos mais recentes devido ao fato de que estes sugerem gaps que provavelmente ainda não foram preenchidos.

Foram então considerados para a análise: os três artigos mais citados, as três últimas citações dos três artigos mais citados, os três últimos artigos mais citados, o último artigo dos dois 
autores mais citados e o último artigo publicado no período da bibliometria. A opção pela escolha de artigos mais recentes, sendo nove artigos do ano de 2017, serve justamente para que se possam analisar os assuntos mais emergentes.

Quatro tendências principais para pesquisas futuras sobre IUE foram identificadas (agrupadas no Anexo 1):

1) Desenvolver iniciativas políticas;

2) Pesquisar características comuns de pessoas envolvidas;

3) Propor modelos de interação;

4) Pesquisar fatores críticos de sucesso.

Dentro deste contexto, é possível inter-relacionar os aspectos aos modelos emergentes, visto que a evolução do assunto é crescente nos últimos anos, sendo um tema recente e proposto o aprofundamento dos estudos sob estas tendências de pesquisa.

\section{A Universidade de Twente como um Modelo de Ações Práticas}

Nesta segunda parte será apresentado, através por meio de um estudo de caso descritivo e exploratório (Santos, 2008a, 2008b), um modelo emergente e de sucesso, que levou ao desenvolvimento regional e expansão da universidade, onde o sucesso é destacado em vários trabalhos (Hospers \& Benneworth, 2012).

Este caso é analisado por meio de uma questão norteadora: "o modelo atende as lacunas e oportunidades destacadas na análise de gaps científicos realizada na análise bibliométrica?". A hipótese inicial é que sim, já que a universidade é vista como um modelo emergente e vem impulsionando o desenvolvimento regional (Hospers \& Benneworth, 2012; SánchezBarrioluengo \& Benneworth, 2018).

A Universidade de Twente (UT) é uma instituição de ensino superior público, localizada na região de Twente, na cidade de Enschede, na Holanda. A UT possui aproximadamente 3000 funcionários e 9700 alunos, com cursos de graduação e pós-graduação em engenharia, ciências sociais e comportamentais. É uma universidade estabelecida na década de sessenta, como uma estratégia para melhorar a região de Twente.

A cidade e a universidade trabalham juntas para o desenvolvimento econômico regional. A Universidade tem seu campus construído em uma propriedade rural nos arredores da cidade de Enschede, na Holanda. Foi criada em 1961 em resposta a sérios problemas econômicos regionais, problemas como resultado do declínio dos têxteis. Apesar de trabalhar frequentemente com a municipalidade anfitriã (Enschede), a universidade construiu conexões na região para construir uma missão corporativa "pós-têxtil", com empresas parceiras e graduados espalhados por toda a região.

Desde 1979, a universidade tem se envolvido ativamente com empresas na região, e em 1984, iniciou seu renomado programa de "spin-offs", tendo apoiado a criação de mais de setecentas empresas até hoje, com mais de cinco mil na região (Hospers \& Benneworth, 2012). A universidade usou sua reputação de pesquisa de classe mundial para convencer os parceiros locais a financiar atividades compartilhadas, que apoiavam a missão regional. Um banco de desenvolvimento agrícola e uma agência de desenvolvimento regional financiaram um centro 
de tecnologia na universidade, criando mais tarde um fundo de capital semente para identificar mais oportunidades de investimento em empresas nascentes.

Após a instalação da UT, o município desenvolveu-se ainda mais, expandindo-se para uma área de mais de 40 hectares onde foi criado um parque científico e tecnológico, que foi preenchido ao longo do tempo por empresas que trabalham em estreita colaboração com a universidade. $\mathrm{O}$ parque científico é claramente um projeto de desenvolvimento econômico bem-sucedido, sugerindo ainda mais potencial para o desenvolvimento econômico da universidade.

A partir do final da década de 1990, a universidade promoveu a ideia de um Parque do Conhecimento, ampliando o parque científico para mais de 100 hectares, criando um centro de atividades regionais de alta tecnologia. A universidade iniciou este desenvolvimento para fornecer recursos para a modernização de seu próprio campus. O Parque do Conhecimento chamou a atenção de dois atores distintos, a universidade e a cidade, que o incorporaram em seu desenvolvimento, políticas e instrumentos para o sucesso do plano.

Mas não só localmente o projeto foi bem sucedido. A integração com mais municípios foi necessária, estimulando assim o desenvolvimento da região. Duas iniciativas foram implementadas, sendo uma delas Twente Network City, representando os quatro principais municípios urbanos, e a política nacional do Ministério de Assuntos Econômicos, que adotou o parque tecnológico como um dos três "parques científicos estratégicos nacionais" (Benneworth et al., 2010).

A presença da universidade ajudou a atrair algumas empresas de alta tecnologia que queriam recrutar diplomados da UT e trabalhar com spin-offs. Essas empresas, como Lucent, Logica e Ericsson, por sua vez, construíram instalações emblemáticas. A inovação no parque apoiou não apenas a economia de Enschede, mas também o apoio a empresas em toda a região.

Essas ações se juntam para sugerir um conjunto de modos de "engajamento urbano" pelas universidades, que vai além do "standalone" ou do "incubator" e do "science park", como modelo dominante, cuja principal característica é contribuir para o desenvolvimento regional. A universidade tem um ecossistema empreendedor, alinhado com as necessidades e interesses regionais das indústrias locais, incorporando redes para apoiar e facilitar o empreendedorismo e impulsionar a inovação (Romme, et al, 2016).

A inovação e o empreendedorismo têm sido citados como a natureza da universidade, com um forte compromisso com o impacto social e econômico na região de Twente. Há muitas atividades empreendedoras, o Centro de Negócios e Tecnologia Twente (BTC-Twente), programas de startup e spin-off, cursos (de cursos abertos a doutorado e o PD.Eng. (um programa de doutorado profissional em engenharia aplicado a empresas e à sociedade), laboratórios (Designlab, Nanolab, etc.), Kennispark e outros.

A UT desenvolveu estratégias e ações futuras, posicionando a universidade como um centro de empreendedorismo acadêmico de classe mundial, compartilhando histórias de sucesso, envolvendo funcionários e alunos no processo de melhoria, e projetando um currículo para reforçar uma atitude empreendedora. Algumas atividades ajudam as empresas em fase inicial a aceleração e crescimento, proporcionando facilidades de financiamento e atribuindo espaço de trabalho aos empresários, por meio de instalações partilhadas. $\mathrm{O}$ contato ativo e proativo com 
a empresa e a sociedade regional impulsiona o desenvolvimento de parceiros estratégicos, estimulando talentos e desenvolvendo novas habilidades em estudantes e parceiros.

O ecossistema empreendedor da UT é composto por uma combinação de recursos humanos, comerciais (financeiros) e tecnológicos (físicos). Os recursos humanos são o elemento mais importante do sucesso da UT no desenvolvimento de uma universidade empreendedora, da alta administração aos estudantes. Recursos financeiros são fundamentais para um efetivo sistema empresarial. Pessoas com competência em gestão de recursos gerenciam o financiamento público, fazendo a coisa certa, deixando as demais envolvidas nas atividades práticas. Além disso, a região de Twente contém um grande número de empresas e investidores privados interessados em investir em startups, muitas vezes em setores relacionados, ou fornecendo serviços complementares aos seus. Sobre o recurso físico, as instalações facilitam as conexões para impulsionar o crescimento do ecossistema empreendedor de alta tecnologia. Existe um parque tecnológico próximo da universidade, que ajuda a criar uma vantagem regional. Outras instalações, como laboratórios, são compartilhadas no campus. Esta pesquisa resulta em troca de conhecimento, desenvolvimento de currículo, contratos de consultoria, colaboração e orientação para estudantes, empreendedores e novas startups (Meerman, 2015).

Entre as principais atividades desenvolvidas relacionadas ao empreendedorismo, inovação e relação universidade-empresa, além de melhorar o desenvolvimento regional, estão:

- Kennispark - O Kennispark é a principal atividade que impulsiona a inovação e o desenvolvimento regional. Esse é um dos mais completos e empreendedores campus de inovação de alta tecnologia na Holanda e na Europa. Existem 430 empresas inovadoras, com recursos e instalações inovadoras, ao lado da UT. Algumas das atividades oferecidas incluem treinamento empresarial de empreendedorismo extracurricular, workshops, suporte a startup, rede, pesquisa de marketing e o uso de instalações conjuntas. São mais de 100 eventos educacionais por ano (workshops, cursos, fóruns). O Kenispark oferece uma parceria de negócios, chamada "Portal para Inovação" e "Loja de Ciências" para o desenvolvimento de ideias inovadoras, para alunos, pesquisadores e sociedade da UT (Kennispark Twente, 2018).

- Novet-T - É a força motriz por trás do ecossistema para a inovação de alta tecnologia e empreendedorismo em Twente e arredores, com base no Kennispark. Eles conectam pessoas, conhecimento correto, redes (inter)nacionais de investidores, cientistas, empreendedores e talentos. A ambição do Novel-T é tornar-se o melhor ecossistema de desempenho para inovação e empreendedorismo na Europa. Os fundadores da Fundação Novel-T são a Universidade de Twente, Saxion, Município de Enschede, Região Twente e Província de Overijssel. Juntas, as forças combinadas devem trabalhar no futuro da região de Twente. O Novel-T oferece aos empreendedores e iniciantes o acesso a um ecossistema dinâmico, conectando empreendedorismo e inovação de alta tecnologia, com foco na cooperação entre instituições de conhecimento e empresas (Novel-T, 2018).

- MESA + Nanolab - A MESA + Nanolab desenvolve pesquisa que gera um faturamento anual de $€ 50$ milhões, estabeleceu 50 spin-offs de alta tecnologia e criou 1.000 empregos na região. O centro também compartilha seus laboratórios com parceiros da indústria para desenvolvimento de protótipos, testes e uso de 
equipamentos, levando a $40 \%$ dos usuários externos. A pesquisa e análise em nanoescala são realizadas em laboratórios de alto padrão (MESA+Institute, 2018).

- NIKOS - O centro acadêmico de empreendedorismo na Holanda, desenvolveu atividades de treinamento (cursos, workshops) para diferentes grupos e nível de conhecimento. É um grupo de pesquisa para empreendedorismo e comportamento empreendedor, estratégia e negócios internacionais, gerenciamento de inovação e networking, marketing digital, inovação de modelos de negócios e desenvolvimento de negócios (NIKOS, 2018).

- CHEPS - O Centro de Estudos de Políticas de Educação Superior é um instituto de pesquisa que oferece pesquisa, treinamento e consultoria sobre vários aspectos da política de ensino superior, particularmente a partir de uma perspectiva comparativa internacional. Há muitos projetos que estão sendo desenvolvidos como o RUNIN - O papel das universidades em inovação e desenvolvimento regional que treinam pesquisadores sobre como as universidades contribuem para a inovação e o crescimento econômico em suas regiões. Este projeto recebeu financiamento do Horizonte 2020 da União Européia para pesquisar como as universidades cumprem sua terceira missão sobre a indústria regional e explorar o alcance do envolvimento das universidades com empresas e instituições regionais (CHEPS, 2018).

- BTC-Twente - O Centro de Negócios e Tecnologia Twente oferece escritórios flexíveis, instalações comerciais, salas e laboratórios para empresas inovadoras, startups e empresas em crescimento. Mais de 700 empresas começaram na BTC que é a primeira incubadora de empresas na Holanda é muito importante para a região de Twente, em plena expansão. Os interessados em BTC-Twente têm a escolha de 4 edifícios diferentes em Enschede (BTC, 2018).

- Programas de Pós-Mestrado - A UT oferece vários cursos. Um dos destaques no relacionamento Universidade-Indústria e Sociedade é o Doutorado Profissional em Engenharia (PDEng), que pode ser concluído em dois anos. Juntamente com a vida empresarial, o PDEng treina pessoas que podem criar designs criativos e inovadores de alta qualidade para problemas complexos de design em um contexto multidisciplinar (UT, 2018).

- Designlab - A University of Twente desenvolveu a iniciativa DesignLab para alimentar a missão "high tech, human touch" da organização. A combinação de alta tecnologia e toque humano foi uma das pontas de lança do futuro, a fim de consolidar a posição única das universidades como uma "universidade dual-core", com uma forte faculdade de ciências e engenharia, de um lado, e uma social. Faculdade de Ciências do outro (Designlab, 2018). Tem a missão de integrar a experiência de ambos os núcleos acadêmicos em "science2design4society", o que significa que o conhecimento de design é usado para disponibilizar novas tecnologias para os usuários e que, juntamente com os mais recentes conhecimentos em humanidades e negócios, são usados para lidar problemas na sociedade contemporânea (Eggink, 2015).

- Outros - Diversas atividades podem ser mencionadas neste artigo. As atividades de engajamento realizadas incluem a "Innovation Lecture Series", o "Science Cafe 
Enschede" e a "Open House University of Twente", que estimulam as percepções do público sobre inovação e empreendedorismo. O projeto da escola de verão internacional "Curiousu" e o "Startify" do ano anterior têm como alvo bacharel e mestrandos de todo o mundo, oferecendo a eles uma seleção de cursos acadêmicos, que incluem os campos de pesquisa mais populares em empreendedorismo e gerenciamento de riscos. Esses papéis adicionais na educação para o empreendedorismo, atendidos pela UT e pelo Kennispark, ajudam a criar uma cultura organizacional que se alinha à visão da universidade (Meerman, 2015).

Dada a descrição das ações de IUE da UT, nota-se que os principais gaps científicos destacados no Anexo 1 são desenvolvidos pela universidade e apresentadas no Quadro 1:

Quadro 1 - Atendimento a lacunas atuais da IUE

\begin{tabular}{|c|c|}
\hline Ações desenvolvidas pela UT & Lacuna apontada por: \\
\hline $\begin{array}{l}\text { A UT busca o desenvolvimento de iniciativas políticas para a IUE. Isso é caracterizado no } \\
\text { ecossistema baseado na Quadruple Helix. O impacto regional é destacado em diversos trabalhos } \\
\text { e os pesquisadores da universidade se envolvem ativamente com a indústria, governo e } \\
\text { sociedade. Em projetos atuais de pesquisa, como os apresentados pelo CHEPS e NIKOS, há a } \\
\text { busca por mecanismos de gestão e monitoramento das interações. }\end{array}$ & $\begin{array}{l}\text { (P. D’Este \& Patel, 2007); } \\
\text { (Bruneel, D’Este, \& Salter, } \\
\text { 2010) }\end{array}$ \\
\hline $\begin{array}{l}\text { Há o engajamento de atividades IUE e a aproximação de ambas as partes da interação, onde } \\
\text { muitas pesquisas e ações práticas são fomentadas por empresas e governo através de iniciativas } \\
\text { políticas. }\end{array}$ & $\begin{array}{l}\text { (Bekkers \& Bodas Freitas, } \\
\text { 2008). }\end{array}$ \\
\hline $\begin{array}{l}\text { O Designlab e o CHEPS desenvolvem pesquisas atuais baseadas em comportamento humano } \\
\text { em sociedade visando a eficácia em processos de ensino e aprendizagem e o engajamento em } \\
\text { ações práticas. Isso leva a pesquisas de características de pessoas envolvidas no processo. }\end{array}$ & (Zhao \& Cai, 2017). \\
\hline $\begin{array}{l}\text { Há maneiras independente de IUE que se baseiam em modelos de interação baseados na } \\
\text { Inovação Aberta. Isto permite que as partes encontrem maneiras de desenvolver projetos de } \\
\text { forma independente, como as ações que acontecem no Novel-T e Designlab. }\end{array}$ & (Kirs, Karo, \& Lumi, 2017). \\
\hline $\begin{array}{l}\text { A Novel-T atua como uma facilitadora na transferência de tecnologia e crescimento de mercado, } \\
\text { favorecendo a IUE por meio de diversas iniciativas públicas em sua política. Há treinamentos } \\
\text { constantes, cursos abertos a comunidade (sociedade e academia), funcionando como um } \\
\text { catalizador de ações. }\end{array}$ & (Kunttu, 2017). \\
\hline $\begin{array}{l}\text { São inúmeros os estudos que apresentam os fatores críticos de sucesso, os modelos utilizados, } \\
\text { as patentes, projetos e iniciativas políticas em todas as ações da UT. Estas estão presentes em } \\
\text { artigos, trabalhos de conclusão, e em comunicação direta com toda uma comunidade, local, } \\
\text { nacional e internacional. }\end{array}$ & $\begin{array}{l}\text { (Villani, Rasmussen, \& } \\
\text { Grimaldi, 2017); (Azagra- } \\
\text { Caro et al, 2017); (Huggins } \\
\text { \& Prokop, 2017); (Strand et } \\
\text { al., 2017); (Wang, Ma, } \\
\text { Liao, \& Du, 2017). }\end{array}$ \\
\hline $\begin{array}{l}\text { Há foco em modelos de interação focados em desenvolvimento científico e tecnológico, com } \\
\text { bases que vão além da Industria 4.0, mas também caminham para uma Sociedade } 5.0 \text { e Educação } \\
4.0 \text { em ações desenvolvidas pela BMS e Faculdade de Engenharia. }\end{array}$ & $\begin{array}{l}\text { (Ibarra, Igartua, \& } \\
\text { Ganzarain, 2017). }\end{array}$ \\
\hline
\end{tabular}

Fonte: Elaboração própria 


\section{Conclusão}

A literatura sobre IUE foi analisada neste artigo por meio de uma análise bibliométrica para explorar e descrever este campo de pesquisa científica. Esta bibliometria apresenta como principal contribuição científica a identificação dos principais autores e suas obras que podem fundamentar no desenvolvimento dessa teoria e que poderão servir de base para pesquisas futuras. Além disso, realiza o mapeamento do estado da arte sobre o tema, pois faz a sistematização da literatura sobre IUE, o apontamento de autores, periódicos, países, publicações e instituições com grande relevância para este campo, bem como a identificação dos gaps científicos que foram propostos para futuras oportunidades de pesquisa relatadas nos artigos mais recentes dos autores mais citados.

Quatro tendências principais para pesquisas futuras sobre IUE foram identificadas: desenvolver iniciativas políticas, pesquisar características comuns de pessoas envolvidas, propor modelos de interação e pesquisar fatores críticos de sucesso. Dentro deste contexto, é possível inter-relacionar os aspectos aos modelos emergentes, como no modelo da Universidade de Twente, visto que o mesmo atende as lacunas previstas na análise bibliométrica.

Como principal contribuição aplicada, este trabalho pode auxiliar a pesquisa e as práticas operacionais de IUE, ao nortear o acesso à literatura considerada importante, atualizada e referência sobre o tema. Como a IUE é uma abordagem relativamente nova, evidenciada no crescimento das publicações a partir de 2007, eles podem enfrentar incertezas e desafios antes ou durante a implementação, fazendo necessário a determinação cada vez mais precisa de fatores críticos de sucesso, característica dos envolvidos, desenvolvimento de políticas e modelos de gestão. À complementação e evolução bibliométrica nesta pesquisa também aponta que a colaboração universidade-empresa é cada vez mais importante, com benefícios a toda a sociedade. Como visto na Universidade de Twente, as atividades desenvolvidas podem ser diversas, onde todas contribuem positivamente para o desenvolvimento local. Isso confirma a base teórica de que universidades e empresas devem trabalhar juntas, contribuindo para o desenvolvimento econômico local, visando um modelo de inovação aberta, baseada no conceito de Quadruple Helix.

Sugere-se que as universidades brasileiras incorporem um modelo de interação e que isso seja visto em três escalas diferentes. No mais alto nível, é claro, deve haver espaço para universidades trabalharem para o desenvolvimento regional. Um parque tecnológico pode ser o topo deste espaço, mas se pode começar com um laboratório ou outro tipo de espaço de trabalho, destinado a compartilhar a pesquisa com a sociedade. Em nível intermediário, as empresas devem estar diretamente conscientes do plano para o desenvolvimento dessa interação, pois podem fomentar projetos e dar vida às ações desenvolvidas. Na corrida pela competitividade dos negócios globais, é importante estimular a inovação nessa parceria. Em um nível inferior, o desenvolvimento de habilidades por meio de novos modelos de ensino e aprendizagem devem ser estabelecidos, deixando de fora os modelos tradicionalistas e ultrapassados, focados na produção, na execução de ordens, não na criatividade e inovação. 


\section{Agradecimentos}

A FAPESP - Fundação de Apoio à Pesquisa e Ensino, por financiar a pesquisa por meio de Bolsa de Pesquisa no Exterior, Processo n ${ }^{\circ}$ 2018/02625-1.

\section{Referências}

Afonso, O., Monteiro, S., \& Thompson, M. (2012). A GROWTH MODEL FOR THE QUADRUPLE HELIX. Journal of Business Economics and Management, 13(5), 849865. https://doi.org/10.3846/16111699.2011.626438

Azagra-Caro, J. M., Barberá-Tomás, D., Edwards-Schachter, M., \& Tur, E. M. (2017). Dynamic interactions between university-industry knowledge transfer channels: A case study of the most highly cited academic patent. Research Policy, 46(2), 463-474. https://doi.org/10.1016/j.respol.2016.11.011

Bekkers, R., \& Bodas Freitas, I. M. (2008). Analysing knowledge transfer channels between universities and industry: To what degree do sectors also matter? Research Policy, 37(10), 1837-1853. https://doi.org/10.1016/j.respol.2008.07.007

Bornmann, L., Haunschild, R., \& Marx, W. (2016). Policy documents as sources for measuring societal impact: how often is climate change research mentioned in policyrelated documents? Scientometrics, 109(3), 1477-1495. https://doi.org/10.1007/s11192016-2115-y

Bruneel, J., D'Este, P., \& Salter, A. (2010a). Investigating the factors that diminish the barriers to university-industry collaboration. Research Policy, 39(7), 858-868. https://doi.org/10.1016/j.respol.2010.03.006

BTC. (2018). BTC Twente BV. Retrieved October 5, 2018, from https://www.btc-twente.nl/

Calcagnini, G., Favaretto, I., Giombini, G., Perugini, F., \& Rombaldoni, R. (2016). The role of universities in the location of innovative start-ups. Journal of Technology Transfer, 41(4), 670-693. https://doi.org/10.1007/s10961-015-9396-9

CHEPS. (2018). Home | CHEPS.

Chesbrough, H., \& Schwartz, K. (2007). Innovating Business Models with Co-Development Partnerships. Research-Technology Management, 50(1), 55-59. https://doi.org/10.1080/08956308.2007.11657419

Chesbrough, H. W. (2003). Open Innovation: The New Imperative for Creating and Profiting from Technology. Harvard Business School Press, Boston. (Vol. 2006). https://doi.org/10.1111/j.1467-8691.2008.00502.x

Clarysse, B., Wright, M., \& Van de Velde, E. (2011). Entrepreneurial Origin, Technological Knowledge, and the Growth of Spin-Off Companies. Journal of Management Studies, 48(6), 1420-1442. https://doi.org/10.1111/j.1467-6486.2010.00991.x

Cohen, W. M., Nelson, R. R., \& Walsh, J. P. (2002). Links and Impacts: The Influence of Public Research on Industrial R\&D. Management Science, 48(June 2015), 1-23. https://doi.org/10.1287/mnsc.48.1.1.14273 
College, P., \& Road, A. H. (2004). The evolution of the entrepreneurial university Henry Etzkowitz. Technology, 1(1), 64-77. Retrieved from http://inderscience.metapress.com/index/VFP58MEACN34AXNM.pdf

D’Este, P., Guy, F., \& Iammarino, S. (2013). Shaping the formation of university-industry research collaborations: What type of proximity does really matter? Journal of Economic Geography, 13(4), 537-558. https://doi.org/10.1093/jeg/lbs010

D'Este, P., \& Patel, P. (2007). University-industry linkages in the UK: What are the factors underlying the variety of interactions with industry? Research Policy, 36(9), 1295-1313. https://doi.org/10.1016/j.respol.2007.05.002

D’Este, P., \& Perkmann, M. (2011). Why do academics engage with industry? The entrepreneurial university and individual motivations. Journal of Technology Transfer, 36(3), 316-339. https://doi.org/10.1007/s10961-010-9153-z

Davey, T., Baaken, T., Galan-Muros, V., \& Meerman, A. (2011). The State of European University-Business Cooperation: Final Report-Study on the cooperation between Higher Education Institutions and public and private organisations in Europe. Science Marketing - Science-to-Business Marketing Research Centre, 1-141.

Designlab. (2018). Home | DesignLab | University of Twente.

Deželan, T., Laker, J., \& Pavlin, S. (2016). What Determines Enterprises' Perceptions of Future Development in Higher Education - Strange Bedfellows? European Journal of Education, 51(1), 107-125. https://doi.org/10.1111/ejed.12169

Eggink, W. (2015). Designlab, making space for doing design as a process. In 17th International Conference on Engineering and Product Design Education, E and PDE 2015 (pp. 112-117). Retrieved from https://www.scopus.com/inward/record.uri?eid=2s2.0-84958212476\&partnerID=40\&md5=a8c1933f933c9a8736f5ac5a29f43606

Etzkowitz, H. (2013). Anatomy of the entrepreneurial university. Social Science Information, 52(3), 486-511. https://doi.org/10.1177/0539018413485832

Etzkowitz, H., \& Leydesdorff, L. (1997). Universities and the global knowledge economy : a triple helix of university-industry-government relations / edited by Henry Etzkowitz and Loet Leydesdorff. Continuum, London. Science, Technology and the International Political Economy Series, 184. Retrieved from http://www.lavoisier.fr/livre/notice.asp?id=OS3WXKAAXL2OWP

Etzkowitz, H., \& Ranga, M. (2010). A Triple Helix System for Knowledge-based Regional Development : From “ Spheres ” to "Spaces ." VIII Triple Helix Conference, 1-29.

Etzkowitz, H., Webster, A., \& Healey, P. (1998). Capitalizing knowledge : new intersections of industry and academia. SUNY series, frontiers in education.

European Comission. (2018). Education, Youth, Sport and Culture | European Commission. Retrieved April 10, 2018, from https://ec.europa.eu/info/departments/education-youthsport-and-culture_en

Fallis, A. . (2013). El Desarrollo Regional y las Encubadoras de Empresas. Journal of Chemical Information and Modeling, 53(9), 1689-1699. 
https://doi.org/10.1017/CBO9781107415324.004

Ferreira, M. P., Santos, J. C., de Almeida, M. I. R., \& Reis, N. R. (2014). Mergers \& acquisitions research: A bibliometric study of top strategy and international business journals, 1980-2010. Journal of Business Research, 67(12), 2550-2558. https://doi.org/10.1016/j.jbusres.2014.03.015

Freeman, C. (1988). Japan: a new national system of innovation? Technical Change and Economic Theory. Retrieved from http://www.lem.sssup.it/WPLem/files/dosietal_1988_V.pdf

Gil, A. C. (2002). Como elaborar projetos de pesquisa. Como Elaborar Projetos de Pesquisa. https://doi.org/10.1111/j.1438-8677.1994.tb00406.x

Gomez-Jauregui, V., Gomez-Jauregui, C., Manchado, C., \& Otero, C. (2014). Information management and improvement of citation indices. International Journal of Information Management, 34(2), 257-271. https://doi.org/10.1016/j.ijinfomgt.2014.01.002

Guerrero-Bote, V. P., \& Moya-Anegón, F. (2012). A further step forward in measuring journals' scientific prestige: The SJR2 indicator. Journal of Informetrics, 6(4), 674-688. https://doi.org/10.1016/j.joi.2012.07.001

Hospers, G.-J., \& Benneworth, P. (2012). Innovation in an old industrial region: the case of Twente. International Journal of Learning and Intellectual Capital, 9(1-2), 6-21. https://doi.org/10.1504/IJLIC.2012.043978

Huang, Y., Huang, Q., Ali, S., Zhai, X., Bi, X., \& Liu, R. (2016). Rehabilitation using virtual reality technology: a bibliometric analysis, 1996-2015. Scientometrics, 109(3), 15471559. https://doi.org/10.1007/s11192-016-2117-9

Huggins, R., \& Prokop, D. (2017). Network structure and regional innovation: A study of university-industry ties. Urban Studies, 54(4), 931-952.

https://doi.org/10.1177/0042098016630521

Ibarra, D., Igartua, J. I., \& Ganzarain, J. (2017). BUSINESS MODEL INNOVATION IN INDUSTRY 4.0: THE CASE OF A UNIVERSITY-INDUSTRY EXPERIENCE IN SMES (pp. 5877-5886). https://doi.org/10.21125/inted.2017.1374

IIASA - The World in 2050. (2018). Retrieved April 9, 2018, from http://www.iiasa.ac.at/web/home/research/twi/TWI2050.html

Kennispark Twente. (2018). Kennispark Twente Home Page. Retrieved October 5, 2018, from https://www.kennispark.nl/

Kirs, M., Karo, E., \& Lumi, P. (2017). Strategic behaviour of research groups within the entrepreneurial university policy rhetoric: The Estonian biotechnology sector. Science and Public Policy, 44(6), 802-820. https://doi.org/10.1093/scipol/scx015

Kunttu, L. (2017). Educational Involvement in Innovative University-Industry Collaboration. Technology Innovation Management Review, 7(12). https://doi.org/http://doi.org/10.22215/timreview/1124

Laursen, K., Reichstein, T., \& Salter, A. (2011). Exploring the Effect of Geographical Proximity and University Quality on University-Industry Collaboration in the United 
Kingdom. Regional Studies, 45(4), 507-523.

https://doi.org/10.1080/00343400903401618

Lehmann, E. E., \& Menter, M. (2016). University-industry collaboration and regional wealth. Journal of Technology Transfer, 41(6), 1284-1307. https://doi.org/10.1007/s10961-0159445-4

Medeiros, I. L. De, Vieira, A., Braviano, G., \& Gonçalves, B. S. (2015). Revisão Sistemática e Bibliometria facilitadas por um Canvas para visualização de informação. Revista Brasileira de Design Da Informação, 12(1), 93-110.

Meerman, A. (2015). University of Twente: The entrepreneurial university of the Netherlands through hi-tech and human touch. In Good Practices UIIN.

Melink, M., Pušnik, T., \& Pavlin, S. (2014). EMCOSU - Emcosu. Retrieved from http://www.emcosu.eu/en/emcosu/

MESA+Institute. (2018). MESA+ Nanolab | NanoLab | MESA+ Institute for Nanotechnology. Retrieved October 5, 2018, from https://www.utwente.nl/en/mesaplus/infrastructure/nanolab/

Motohashi, K. (2005). University-industry collaborations in Japan: The role of new technology-based firms in transforming the National Innovation System. Research Policy, 34(5), 583-594. https://doi.org/10.1016/j.respol.2005.03.001

NIKOS. (2018). NIKOS - Innovation Entrepreneurship - Home Page. Retrieved October 5, 2018, from https://www.utwente.nl/en/bms/nikos/

Novel-T. (2018). Novel-T | innovate \&amp; accelerate Home Page.

Park, H. W., \& Leydesdorff, L. (2010). Longitudinal trends in networks of universityindustry-government relations in South Korea: The role of programmatic incentives. Research Policy, 39(5), 640-649. https://doi.org/10.1016/j.respol.2010.02.009

Parveen, S., Senin, A. A., \& Umar, A. (2015). A Quadruple Helix Open Innovation Model Approach. International Journal of Economics and Financial Issues, 5(5), 10-11. Retrieved from http:www.econjournals.com

Payne, A. F. (1921). MERITS AND DEFECTS OF PRESENT PRACTISES OF COOPERATION BETWEEN UNIVERSITIES AND INDUSTRY. SCHOOL AND SOCIETY, 335, 607-613. Retrieved from http://apps.webofknowledge.com/full_record.do?product=WOS\&search_mode=General Search\&qid=2\&SID=7A8e2BEIyHUmjbzkf3u\&page $=1 \&$ doc $=2 \&$ cacheurlFromRightCli $\mathrm{ck}=$ no

Perkmann, M., \& Salter, A. (2012). How to create Productive Partnerships With universities. MIT Sloan Management Review, ..., 53(4), 79-88. https://doi.org/10.1007/s13398-0140173-7.2

Perkmann, M., \& Walsh, K. (2009). The two faces of collaboration: impacts of universityindustry relations on public research. Industrial and Corporate Change, 18(6), 10331065. https://doi.org/10.1093/icc/dtp015

Person, A. E., \& Rosenbaum, J. E. (2006). Educational outcomes of labor-market linking and 
job placement for students at public and private 2-year colleges. Economics of Education Review, 25(4), 412-429. https://doi.org/10.1016/j.econedurev.2005.09.005

Ponds, R., van Oort, F., \& Frenken, K. (2010). Innovation, spillovers and university-industry collaboration: An extended knowledge production function approach. Journal of Economic Geography, 10(2), 231-255. https://doi.org/10.1093/jeg/lbp036

Ranga, M., \& Etzkowitz, H. (2013). Triple Helix Systems: An Analytical Framework for Innovation Policy and Practice in the Knowledge Society. Industry and Higher Education, 27(4), 237-262. https://doi.org/10.5367/ihe.2013.0165

Ribeiro, V. L. (2018). A economia política dos Estados Unidos e da China pós crise de 2008: interdependência econômica e relações interestatais. Geosul, 33(67), 11-37. https://doi.org/10.5007/2177-5230.2018v33n67p11

Romme, A.G.L.; Roso, M.; van den Toren, J.P.; van der Starre, B. T. (2016). Knowledge triangles in the Netherlands: an entrepreneurial ecosystem approach Knowledge Triangles in the Netherlands.

Sábato, J., \& Botana, N. (1968). La ciencia y la tecnología en el desarrollo futuro de América Latina. Revista de La Integración, 1(3), 15-36. https://doi.org/10.1017/CBO9781107415324.004

Sánchez-Barrioluengo, M., \& Benneworth, P. (2018). Is the entrepreneurial university also regionally engaged? Analysing the influence of university's structural configuration on third mission performance. Technological Forecasting and Social Change. https://doi.org/10.1016/J.TECHFORE.2018.10.017

Santos, C. J. G. Dos. (2008a). Pesquisa exploratória : explorando novos caminhos e novos espaços ! Oficina Da Pesquisa, Apostila 9(2010), 1. Retrieved from http://www.oficinadapesquisa.com.br/APOSTILAS/METODOL/_OF.TIPOS_PESQUIS A.PDF

Santos, C. J. G. Dos. (2008b). Tipos de Pesquisa. Oficina Da Pesquisa, Apostila 9(2010), 1. https://doi.org/10.1002/bit.22591

Science to Business Marketing Research Centre. (2018). S2B. Retrieved April 10, 2018, from https://www.science-marketing.com/

SDSN - Sustainable Development Solutions Network. (2018). Retrieved April 9, 2018, from http://unsdsn.org/

Segarra-Blasco, A., \& Arauzo-Carod, J.-M. (2008). Sources of innovation and industryuniversity interaction: Evidence from Spanish firms. Research Policy, 37(8), 1283-1295. https://doi.org/10.1016/j.respol.2008.05.003

Silva, D. O. da, Bagno, R. B., \& Salerno, M. S. (2013). Modelos para a gestão da inovação: revisão e análise da literatura. Produção, 24(ahead), 477-490. https://doi.org/10.1590/S0103-65132013005000059

Strand, Ø., Ivanova, I., \& Leydesdorff, L. (2017). Decomposing the Triple-Helix synergy into the regional innovation systems of Norway: firm data and patent networks. Quality and Quantity, 51(3), 963-988. https://doi.org/10.1007/s11135-016-0344-z 
Tether, B. S., \& Tajar, A. (2008). Beyond industry-university links: Sourcing knowledge for innovation from consultants, private research organisations and the public science-base. Research Policy, 37(6-7), 1079-1095. https://doi.org/10.1016/j.respol.2008.04.003

Thune, T. (2009). Proximity and Interactive Learning in University-Firm Relationships. Industry and Higher Education, 23(1), 7-16. https://doi.org/10.5367/000000009787641332

Thune, T. (2011). Success Factors in Higher Education-Industry Collaboration: A case study Of collaboration in the engineering field. Tertiary Education and Management, 17(1), 31-50. https://doi.org/10.1080/13583883.2011.552627

Tötterman, H., \& Sten, J. (2005). Start-ups: Business incubation and social capital. International Small Business Journal, 23(5), 487-511. https://doi.org/10.1177/0266242605055909

UIIN. (2018). UIIN - The University Industry Innovation Network. Retrieved April 9, 2018, from https://www.uiin.org/

United Nations. (2015). Transforming our world: the 2030 Agenda for Sustainable Development. In General Assembly Resolution 70/1, 25 September 2015 (Vol. 16301, pp. 1-40). Retrieved from http://unctad.org/meetings/es/SessionalDocuments/ares70d1_es.pdf

UT. (2018). PDEng | PDEng at the UT | Twente Graduate School.

Villani, E., Rasmussen, E., \& Grimaldi, R. (2017). How intermediary organizations facilitate university-industry technology transfer: A proximity approach. Technological Forecasting and Social Change, 114, 86-102. https://doi.org/10.1016/j.techfore.2016.06.004

Wang, Q., Ma, J., Liao, X., \& Du, W. (2017). A context-aware researcher recommendation system for university-industry collaboration on R\&amp;D projects. Decision Support Systems, 103, 46-57. https://doi.org/10.1016/J.DSS.2017.09.001

Zhao, Z., \& Cai, J. (2017). Individual differences, self-efficacy, and Chinese scientists' industry engagement. Information (Switzerland), 8(4). https://doi.org/10.3390/info8040160

\section{Anexo 1:}

Anexo 1 - Gaps científicos

\begin{tabular}{|c|c|c|c|}
\hline Tipo & Título & Lacunas & Oportunidades \\
\hline $\begin{array}{c}3 \text { artigos } \\
\text { mais } \\
\text { citados }\end{array}$ & $\begin{array}{l}\text { University-industry } \\
\text { linkages in the UK: What } \\
\text { are the factors underlying } \\
\text { the variety of interactions } \\
\text { with industry? (P. D'Este } \\
\text { \& Patel, 2007). }\end{array}$ & $\begin{array}{l}\text { Os autores sugerem a busca por iniciativas políticas que } \\
\text { poderiam contribuir para a construção das habilidades } \\
\text { necessárias para integrar os mundos da indústria e da academia. } \\
\text { Sugerem também pesquisas futuras que devem ser destinadas a } \\
\text { identificar as características comuns entre pesquisadores que se } \\
\text { envolvem ativamente com a indústria, e investigar as maneiras } \\
\text { pelas quais eles conseguiram. }\end{array}$ & $\begin{array}{l}\text { Desenvolver iniciativas } \\
\text { políticas. } \\
\text { Pesquisar características } \\
\text { comuns de pessoas } \\
\text { envolvidas } \\
\text { Pesquisar fatores críticos } \\
\text { de sucesso }\end{array}$ \\
\hline
\end{tabular}




\begin{tabular}{|c|c|c|}
\hline & & Propor Modelos de IUE \\
\hline $\begin{array}{l}\text { Investigating the factors } \\
\text { that diminish the barriers } \\
\text { to university- } \\
\text { industry collaboration } \\
\text { (Bruneel, D'Este, \& Salter, } \\
\text { 2010) }\end{array}$ & $\begin{array}{l}\text { O trabalho sugere que deve ser dada uma maior atenção para o } \\
\text { gerenciamento da IUE, buscando políticas de governo e de } \\
\text { administração da universidade menos burocrática, com simples } \\
\text { mecanismos de gestão e monitoramento das interações, já que as } \\
\text { atuais geram por vezes muito mais dificuldades e acabam por } \\
\text { atrapalhar a IUE. }\end{array}$ & $\begin{array}{l}\text { Desenvolver iniciativas } \\
\text { políticas } \\
\text { Propor Modelos de IUE }\end{array}$ \\
\hline
\end{tabular}

Fonte: Elaboração própria

\section{Anexo 1 (continuação):}

Anexo 1 - Gaps científicos

\begin{tabular}{|c|c|c|c|}
\hline Tipo & Título & Lacunas & Oportunidades \\
\hline $\begin{array}{l}3 \text { artigos } \\
\text { mais } \\
\text { citados }\end{array}$ & $\begin{array}{l}\text { Analysing knowledge } \\
\text { transfer channels between } \\
\text { universities and industry: } \\
\text { To what degree do sectors } \\
\text { also matter? (Bekkers \& } \\
\text { Bodas Freitas, 2008). }\end{array}$ & $\begin{array}{l}\text { Os autores comentam que dada a limitação do trabalho, é } \\
\text { necessária a realização de um estudo que aborde todo o pessoal } \\
\text { de uma organização (empresa) que acessa o conhecimento } \\
\text { universitário, avaliando as possibilidades na interação por todos. } \\
\text { Citam que é necessário definir o que e como as empresas se } \\
\text { envolvem na aplicação de publicações científicas, podendo dar a } \\
\text { funcionários a chance de engajamento na academia, se } \\
\text { aproximando mais de pesquisadores da universidade e alunos. }\end{array}$ & $\begin{array}{l}\text { Pesquisar características } \\
\text { comuns de pessoas } \\
\text { envolvidas } \\
\text { Propor Modelos de IUE }\end{array}$ \\
\hline \multirow{3}{*}{$\begin{array}{l}3 \text { últimas } \\
\text { citações } \\
\text { dos } \\
\text { artigos } \\
\text { mais } \\
\text { citados }\end{array}$} & $\begin{array}{l}\text { Individual Differences, } \\
\text { Self-Efficacy, and Chinese } \\
\text { Scientists' Industry } \\
\text { Engagement (Zhao \& Cai, } \\
\text { 2017) }\end{array}$ & $\begin{array}{l}\text { O trabalho sugere que os decisores políticos e os gestores das } \\
\text { universidades precisam prestar mais atenção às mudanças } \\
\text { psicológicas dos acadêmicos para fortalecer sua auto eficácia. } \\
\text { Pesquisas futuras poderiam desenvolver medidas para isto, } \\
\text { combinando escalas existentes com características culturais e } \\
\text { políticas. É necessário explorar como outros níveis de fatores } \\
\text { psicológicos afetam o engajamento acadêmico. Pesquisas podem } \\
\text { examinar estes fatores com o envolvimento dos acadêmicos com } \\
\text { a indústria. }\end{array}$ & $\begin{array}{l}\text { Pesquisar características } \\
\text { comuns de pessoas } \\
\text { envolvidas } \\
\text { Propor Modelos de IUE }\end{array}$ \\
\hline & $\begin{array}{l}\text { Strategic behaviour of } \\
\text { research groups within the } \\
\text { entrepreneurial university } \\
\text { policy rhetoric: the } \\
\text { Estonian biotechnology } \\
\text { sector (Kirs et al., 2017) }\end{array}$ & $\begin{array}{l}\text { Os autores citam a lacuna estrutural no setor de pesquisa e } \\
\text { desenvolvimento da Estônia na combinação de políticas de IUE: } \\
\text { a retórica da universidade empreendedora requer pesquisa } \\
\text { orientada, as empresas requerem capacidades orientadas para a } \\
\text { comercialização e rotinas, esperando que as universidades } \\
\text { encontrem maneiras de desenvolver estes por conta própria. }\end{array}$ & $\begin{array}{l}\text { Desenvolver iniciativas } \\
\text { políticas. }\end{array}$ \\
\hline & $\begin{array}{l}\text { Educational Involvement } \\
\text { in Innovative University- } \\
\text { Industry Collaboration } \\
\text { (Kunttu, 2017) }\end{array}$ & $\begin{array}{l}\text { Este estudo apesar de não apresentar sugestão de pesquisas } \\
\text { futuras, sugere uma variedade de práticas que devem ser } \\
\text { incorporadas a IUE e que incluem envolvimento educacional, } \\
\text { com um impacto positivo sobre essas pesquisas e colaborações, } \\
\text { especialmente em termos de aprendizagem relacional, criação de } \\
\text { conhecimento e compromisso entre as partes e com a sociedade. }\end{array}$ & $\begin{array}{l}\text { Pesquisar fatores críticos } \\
\text { de sucesso } \\
\text { Propor modelos de IUE }\end{array}$ \\
\hline $\begin{array}{l}\text { Último } \\
\text { artigo } \\
\text { publicado } \\
\text { dos } 2 \\
\text { autores } \\
\text { mais } \\
\text { citados }\end{array}$ & $\begin{array}{l}\text { Decomposing the Triple- } \\
\text { Helix synergy into the } \\
\text { regional innovation } \\
\text { systems of Norway: firm } \\
\text { data and patent networks } \\
\quad \text { (Strand et al., 2017) }\end{array}$ & $\begin{array}{l}\text { O estudo não foi aplicado em sua totalidade, mas já identifica } \\
\text { possibilidades para pesquisa, sendo as principais relacionadas a } \\
\text { pesquisar como a indústria percebe as relações, bem como } \\
\text { mensuram a sinergia entre as partes, afim de demonstrar se os } \\
\text { projetos são estáveis. Também comenta que os padrões de } \\
\text { patentes são diferentes entre os setores da indústria e campos } \\
\text { acadêmicos, e isso também deve ser mensurado. }\end{array}$ & $\begin{array}{l}\text { Pesquisar características } \\
\text { comuns de pessoas } \\
\text { envolvidas } \\
\text { Propor modelos de IUE }\end{array}$ \\
\hline
\end{tabular}




\begin{tabular}{|l|l|l|l|}
\hline & $\begin{array}{l}\text { Embora o artigo cita que o contexto da Noruega deve ser } \\
\text { ampliado nos próximos estudos, preferencialmente incluindo } \\
\text { dados e resultados, pode-se também ser realizados estudos em } \\
\text { outras economias, onde se possa apontar como se mensuram os } \\
\text { benefícios e sinergias. }\end{array}$ & $\begin{array}{l}\text { Pesquisar fatores críticos } \\
\text { de sucesso }\end{array}$ & Pesquisar fatores críticos \\
& $\begin{array}{c}\text { Business model innovation } \\
\text { in industry 4.0: the case of } \\
\text { a university-industry } \\
\text { experience in SMES } \\
\text { (Ibarra et al., 2017) }\end{array}$ & $\begin{array}{l}\text { A Industria 4.0 é discutida neste trabalho, pois sugere que essa } \\
\text { abordagem pode aumentar os ganhos e os interesses na IUE, } \\
\text { devendo ser foco em projetos de interação. }\end{array}$ & Propor Modelos de IUE \\
\hline
\end{tabular}

Fonte: Elaboração propria

Anexo 1-Gaps científicos (continuação)

\begin{tabular}{|c|c|c|c|}
\hline Tipo & Título & Lacunas & Oportunidades \\
\hline \multirow{3}{*}{$\begin{array}{c}3 \text { últimos } \\
\text { artigos } \\
\text { mais } \\
\text { citados }\end{array}$} & $\begin{array}{l}\text { How intermediary } \\
\text { organizations } \\
\text { facilitate university- } \\
\text { industry technology } \\
\text { transfer: A proximity } \\
\text { approach (Villani et al., } \\
\text { 2017) }\end{array}$ & $\begin{array}{l}\text { O trabalho cita que por muitos anos, ganhos e dificuldades nas } \\
\text { IUE foram publicadas e que foi necessária a criação de } \\
\text { intermediários para facilitar esta integração (escritórios } \\
\text { incubadoras, centros de pesquisa aplicada), mas faltam } \\
\text { entendimentos conceituais sobre como essas organizações } \\
\text { facilitam a transferência de tecnologia. } \\
\text { Além disso, pesquisas futuras devem ir além destes } \\
\text { intermediários, incluindo outros tipos de organizações, } \\
\text { especialmente emergentes. } \\
\text { Também sugerem que sejam organizadas pesquisas em ciência } \\
\text { colaborativa aberta (redes de colaboração para a pesquisa em } \\
\text { IUE). } \\
\text { Em uma parte do trabalho também é catada a necessidade de } \\
\text { realizar estudos futuros para analisar e avaliar as questões de } \\
\text { proximidade cognitiva entre intermediários e seus clientes, com } \\
\text { o objetivo de identificar mais saídas ou expectativas refinadas } \\
\text { para usar como um desempenho de medida básico. }\end{array}$ & $\begin{array}{l}\text { Desenvolver iniciativas } \\
\text { políticas. } \\
\text { Pesquisar características } \\
\text { comuns de pessoas } \\
\text { envolvidas } \\
\text { Propor Modelos de IUE }\end{array}$ \\
\hline & $\begin{array}{l}\text { Dynamic interactions } \\
\text { between university- } \\
\text { industry knowledge } \\
\text { transfer channels: A case } \\
\text { study of the most highly } \\
\text { cited academic patent } \\
\text { (Azagra-Caro et al., 2017) }\end{array}$ & $\begin{array}{l}\text { Embora o estudo não apresente sugestões diretas, por meio do } \\
\text { que foi desenvolvido é possível comparar os resultados } \\
\text { avaliando na IUE } 3 \text { percepções: o impacto econômico local, o } \\
\text { conhecimento gerado durante as atividades e o método } \\
\text { desenvolvido que se relacionam a patentes. }\end{array}$ & $\begin{array}{l}\text { Pesquisar fatores críticos } \\
\text { de sucesso }\end{array}$ \\
\hline & $\begin{array}{l}\text { Network structure and } \\
\text { regional innovation: A } \\
\text { study of university- } \\
\text { industry ties (Huggins \& } \\
\quad \text { Prokop, 2017) }\end{array}$ & $\begin{array}{l}\text { O estudo focou em cenários universitários apresentando uma } \\
\text { estrutura de rede parcial, que pode ser complementado por } \\
\text { estudos de empresa para empresa e de universidade para } \\
\text { universidade, possibilitando redes de cooperação entre estas. } \\
\text { Outra sugestão é dada para que sejam melhoradas as } \\
\text { centralizações da IUE com áreas específicas abertas a empresas } \\
\text { (acesso direto das empresas a universidade). } \\
\text { Os autores comentam que é necessário apresentar fluxos de } \\
\text { conhecimento para a IUE, podendo ser demonstradas as formas } \\
\text { e os ganhos sobre invenções, patentes, teorias e } \\
\text { desenvolvimento regional. }\end{array}$ & $\begin{array}{l}\text { Pesquisar características } \\
\text { comuns de pessoas } \\
\text { envolvidas } \\
\text { Pesquisar fatores críticos } \\
\text { de sucesso } \\
\text { Desenvolver iniciativas } \\
\text { políticas. } \\
\text { Propor Modelos de IUE }\end{array}$ \\
\hline
\end{tabular}


Avaliado pelo sistema double blind review Editor: Márcio M. Abdalla

\begin{tabular}{|c|c|l|l|}
\hline $\begin{array}{c}\text { Último } \\
\text { artigo } \\
\text { citado }\end{array}$ & $\begin{array}{c}\text { A context-aware researcher } \\
\text { recommendation system } \\
\text { for university-industry } \\
\text { collaboration on R\&D } \\
\text { projects (Wang et al., } \\
2017)\end{array}$ & $\begin{array}{l}\text { É um trabalho de um projeto aplicado, mas os autores comentam } \\
\text { que é necessário medir o desempenho de projetos, pois ainda há } \\
\text { muito trabalho a ser feito para garantir o sucesso de uma IUE. }\end{array}$ & $\begin{array}{l}\text { Pesquisar fatores críticos } \\
\text { de sucesso }\end{array}$ \\
\hline
\end{tabular}

Fonte: Elaboração própria 